\title{
HIERARCHICAL CLUSTERING BAHAN MENU DI KANTIN UNIVERSITAS UNTUK MENUNJANG IMPLEMENTASI SISTEM JAMINAN HALAL
}

\author{
HIERARCHICAL CLUSTERING OF MENU MATERIALS IN \\ THE UNIVERSITY CANTEEN TO SUPPORT IMPLEMENTATION OF \\ HALAL ASSURANCE SYSTEM
}

\author{
Sucipto Sucipto ${ }^{1,2)^{*}}$, Mohammad Syarifuddin Al-Mubarok ${ }^{1)}$, Danang Triagus Setiyawan ${ }^{1,2}$ \\ ${ }^{1)}$ Program Studi Teknologi Industri Pertanian, Universitas Brawijaya \\ Gedung Fakultas Teknologi Pertanian Lantai 5, J1. Veteran Malang 65145, Indonesia \\ Email: ciptotip@ub.ac.id \\ ${ }^{2)}$ Halal Qualified Industry Development (Hal-Q ID), Universitas Brawijaya \\ Gedung Fakultas Teknologi Pertanian Lantai 5, Jl. Veteran Malang, 65145, Indonesia \\ Makalah: Diterima 20 November 2020; Diperbaiki 25 Januari 2021; Disetujui 20 Februari 2021
}

\section{ABSTRACT}

The university canteen serves to fulfill the food need of the academic community in universities. Even though the price is relatively low, the halalness of the menu must be guaranteed. University canteens need to be encouraged to compile documents and implement a halal assurance system (HAS). Creative Land (CL) canteen has 24 tenants, most of them are in Universitas Brawijaya (UB), so the identification of halal control points (HCP) becomes more complex. The identification of HCP materials can be made easier using the clustering method. The research described the various menus and ingredients to determine the ingredient clusters and carry out further treatment. The research used hierarchical clustering and follow-up refers to HAS in Indonesia. Materials were grouped into two groupings, namely critical materials and non-critical materials. Materials do not meet the criteria need for being replaced by halal materials. The results showed that in this canteen, there were 262 menus and 722 ingredients. Material identification was $28.95 \%$ halal-certified materials, and $71.05 \%$ non-halal certified materials, which were consisted of $67.45 \%$ non-critical materials and $3.55 \%$ critical materials. Critical materials can be replaced by halal-certified materials or a halal production process (HPP) statement from the producer, which needs further inspection by Halal Inspection Agency (HIA). The hierarchical clustering method can help group complex canteen menu ingredients and determine appropriate handling to speed up document preparation and application for halal certification.

Keywords: clustering, canteen, halal control point, halal assurance system.

\section{ABSTRAK}

Kantin universitas berfungsi memenuhi kebutuhan pangan seluruh civitas akademika di perguruan tinggi. Meski harganya relatif murah, kehalalan menunya harus dijamin. Kantin universitas perlu didorong untuk menyusun dokumen dan menerapkan sistem jaminan halal (SJH). Kantin Creative Land (CL) memiliki 24 tenant, paling banyak di Universitas Brawijaya (UB), sehingga identifikasi titik kontrol kehalalan (HCP) menjadi lebih kompleks. Identifikasi HCP bahan diduga dapat dipermudah menggunakan metode clustering. Penelitian ini mendeskripsikan beragam menu dan bahan untuk menentukan klaster bahan dan melakukan penanganan lanjutan. Penelitian menggunakan hierarchical clustering dan tindak lanjut mengacu SJH yang berlaku di Indonesia. Bahan dikelompokkan menjadi dua klaster, yakni bahan kritis dan bahan non kritis. Bahan tidak memenuhi kriteria perlu diganti dengan bahan halal. Hasil penelitian menunjukkan pada kantin ini ada 262 menu dan 722 bahan. Identifikasi bahan ada $28,95 \%$ bahan bersertifikat halal dan $71,05 \%$ bahan tidak bersertifikat halal yang terdiri atas $67,45 \%$ termasuk bahan non-kritis dan 3,55\% bahan kritis. Bahan kritis perlu diganti dengan bahan bersertifikat halal atau surat pernyataan proses produksi halal ( $\mathrm{PPH})$ dari produsen yang perlu diperiksa lebih lanjut oleh lembaga pemeriksa halal (LPH). Metode hierarchical clustering dapat membantu pengelompokan bahan menu kantin yang kompleks dan menentukan penanganan yang tepat untuk mempercepat persiapan dokumen dan pengajuan sertifikasi halal.

Kata kunci : clustering, halal control point, kantin, sistem jaminan halal

\section{PENDAHULUAN}

Kantin universitas merupakan salah satu tempat untuk memenuhi kebutuhan pangan civitas akademika selama di kampu s. Meski harga menu diupayakan relatif murah, aspek kehalalan produknya harus diperhatikan. Kebutuhan mengkonsumsi pangan halal bukan hanya bagi muslim, tetapi juga bagi non muslim dengan alasan keamanan (Nurrachmi, 2017). Potensi pemasaran produk halal 
terus meningkat (Supaat et al., 2019; Sukoso, et al., 2020). Pangan halal harus sesuai hukum syariah Islam. Thayyib atau baik adalah sesuatu yang dirasa enak oleh indra atau jiwa, atau tidak menyakitkan dan menjijikkan (Wirawan, et al., 2018). Menurut Sucipto, et al. (2018) kantin halal di perguruan tinggi perlu sertifikasi halal dari lembaga berwenang. Sertifikasi halal kantin mulai pengendalian keamanan pangan cepat saji untuk mendapat sertifikat layak higienitas dari dinas kesehatan, berikutnya proses sertifikasi halal ke lembaga yang berwenang. Langkah awal sebelum mengajukan sertifikasi halal adalah membangun kesadaran pentingnya sertifikasi halal, menyusun dokumen Sistem Jaminan Halal (SJH), dan mengimplementasikan di usaha. Penyusunan dokumen SJH membutuhkan identifikasi dan penelusuran status kehalalan bahan.

Riset penelusuran keamanan pangan seperti Hazard Analysis and Critical Control Points (HACCP) sudah banyak diteliti. Wallace, et al. (2005) menstandarkan penilaian HACCP. Wallace, et al. (2014) telah mendiskusikan kesulitan analisis bahaya dalam HACCP. Osimani et al. (2018) telah mengaudit hieginitas kantin universitas. Osimani et al. (2013) and Osimani et al. (2015) examined system and HACCP produk segar pada kantin universitas. Critical Control Point (CCP) terdiri dari bahaya fisik, kimia, biologi. Penelusuran CCP pada industri es krim telah didiskusikan dengan baik (Allata et al., 2017). Di sisi lain, penelitian implementasi SJH dan penelusuran Halal Control Point (HCP) untuk mendukung SJH masih terbatas. Beberapa penelitian implementasi SJH pada industri pangan (Hasan et al., 2015), restoran syariah (Perdani et al., 2017; Nurmaydha et al., 2018), penelusuran HCP di industri bakery (Perdani, et al., 2018), mie goreng skala kecil (Sucipto, et al., 2016a), waralaba bakso (Sucipto, et al., 2016b). Beberapa riset di atas jumlah menu dan bahan cukup terbatas sehingga relatif sederhana.

Creative Land (CL) merupakan kantin terbesar di Universitas Brawijaya (UB) memiliki 24 tenant dengan beragam menu makanan dan minuman. Kondisi ini membuat penelusuran HCP bahan dan proses lebih kompleks dibanding kantin lain di UB. Penelusuran HCP bahan di usaha kantin mengacu Halal Assurance System (HAS-23102) untuk restoran (LPPOM MUI, 2015). Penelusuran HCP bahan penting guna menyusun matrik bahan dalam dokumen SJH. Karena banyak dan beragam menu dan bahan di kantin CL, maka perlu pendekatan baru dengan sistem clustering.

Sistem clustering diharapkan lebih memudahkan identifikasi dan penelusuran $\mathrm{HCP}$ bahan menu di kantin CL. Tidak ada teknik clustering paling baik, karena aplikasinya spesifik (Singh dan Srivastava, 2020). Teknik clustering dibagi pada soft clustering dan hard clustering. Selanjutnya hard clustering dibagi menjadi partitional dan hierarchical (Saxena et al., 2017). Pada penelitian ini, clustering bahan di kantin CL menggunakan metode hierarchical clustering. Metode ini menganggap tiap objek terkelompok tersendiri, lalu dua objek berdekatan digabung menjadi kelompok lebih kecil (Sitepu et. al., 2011). Metode hierarchical clustering memiliki kelebihan sederhana, mudah dimengerti secara komprehenship, dan jumlah kelompok tidak mesti ditentukan dahulu (Gupta dan Rastogi, 2017). Tidak ada kriteria pasti, yang bebas dari tujuan akhir klasterisasi (Dewi, 2012). Jumlah cluster ditentukan dari dendrogram yang terbentuk dan subyektivitas peneliti. Sesuai HAS 23000, tentang Persyaratan sertifikasi halal (LPPOM MUI, 2012), bahan di kantin CL dikelompokkan 2 klaster, yakni bahan kritis dan bahan non-kritis. Bahan kritis tidak memenuhi kriteria perlu diganti dengan bahan halal. Tujuan penelitian ini mendeskripsikan menu dan bahan untuk menentukan klaster bahan di kantin CL UB. Selain itu, untuk menelusuri bahan yang tidak memenuhi kriteria dan perlu diganti dengan bahan halal.

\section{METODE PENELITIAN}

Penelitian ini menggunakan metode analisis deskriptif. Data primer penelitian diperoleh melalui wawancara pada pengelola kantin CL UB tentang gambaran umum kantin. Wawancara juga dilakukan pada 24 tenant terkait daftar dan diskripsi menu, informasi bahan (nama bahan, merk, produsen, suplier, status bahan mengacu matrik bahan pada HAS-23002 tentang pemenuhan kriteria sistem jaminan halal di restoran). Observasi langsung ke dapur dan outlet 24 tenant untuk memverifikasi hasil wawancara dengan tenant dengan fakta bahan yang digunakan. Dokumentasi berupa data dan foto bahan, kemasan bahan, dan sertifikasi halal bahan dari pemasok. Data sekunder meliputi daftar bahan tidak kritis dari LPPOM MUI dan daftar belanja produk halal LPPOM MUI untuk memverifikasi status kehalalan bahan menu setiap tenant.

Pengolahan data menggunakan metode hierarchical clustering. Tujuan pengelompokan bahan menjadi bahan kritis dan bahan non-kritis. Tahap identifikasi bahan baku dapat dilihat pada Gambar 1

\section{Hierarchical Clustering}

Pada penelitian ini bahan dikelompokkan menggunakan metode Aglomerative Hierachical Clustering. Proses clustering sebagai berikut:

\section{Tahap 1. Atribut dan Nilai Bahan}

Bahan menu dijadikan database besar. Pengolahan data menggunakan software SPSS 19.0. Data nama bahan dimasukkan ke data view SPSS. Nama atribut, nilai, dan kode atribut bahan pada Tabel 1. 


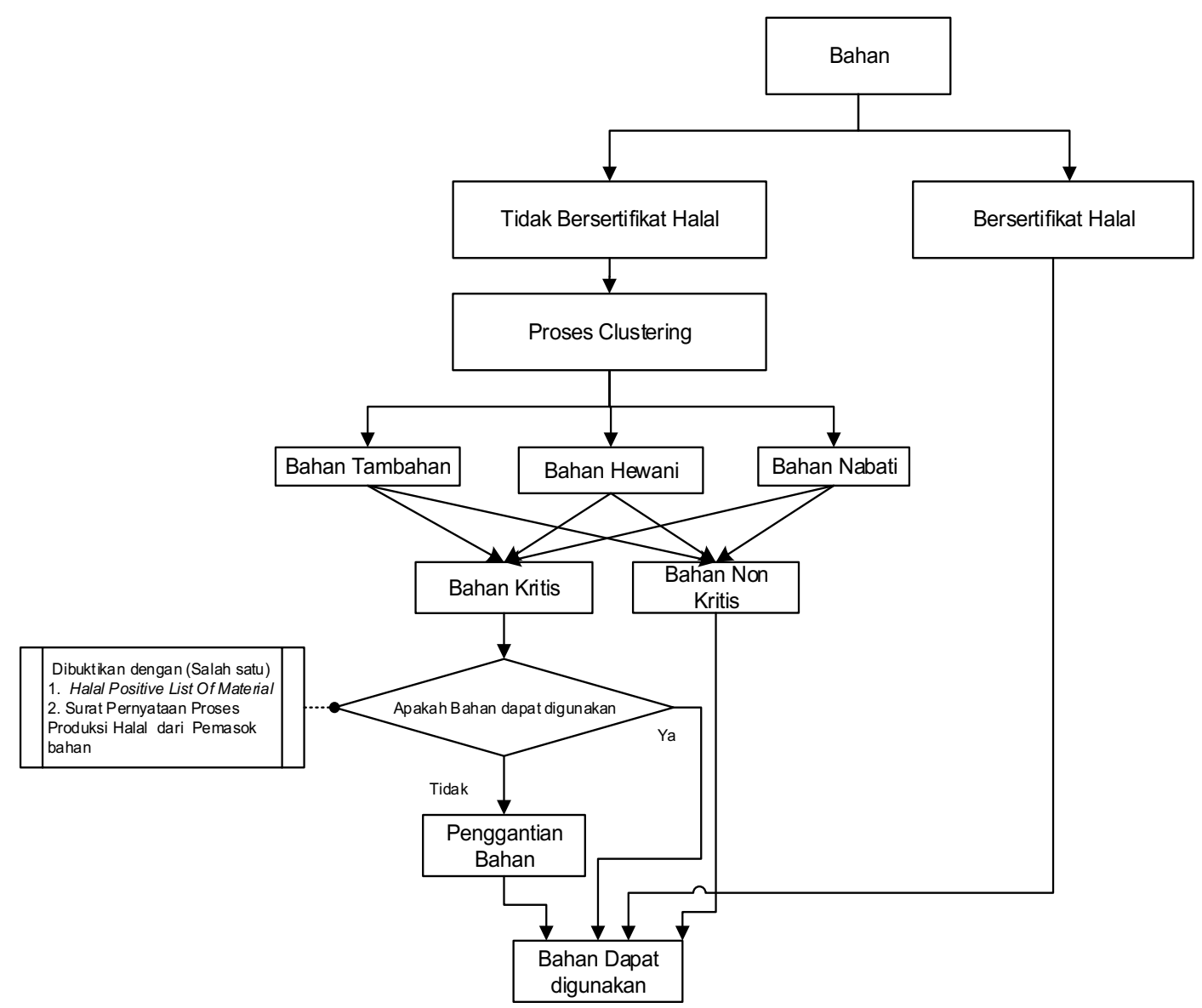

Gambar 1. Diagram Alir Analisis Data

Tabel 1. Atribut, Nilai Bahan, dan Kode Atribut Bahan

\begin{tabular}{|c|c|c|c|c|}
\hline No & Nama Atribut & Keterangan & Nilai & Kode \\
\hline \multirow[t]{3}{*}{1} & Sumber bahan & Sumber bahan adalah asal bahan atau & Bahan nabati, & 1 \\
\hline & & komponen utama pada bahan & Bahan hewani, & 3 \\
\hline & & & Bahan tambahan & 5 \\
\hline \multirow[t]{2}{*}{2} & Jenis bahan & Jenis bahan adalah atribut yang & Bahan segar, & 1 \\
\hline & & $\begin{array}{l}\text { menyatakan ada atau tidak ada } \\
\text { pengolahan }\end{array}$ & Bahan olahan & 5 \\
\hline \multirow[t]{3}{*}{3} & Status pengolahan & Atribut ini menyimpan data status & Pengolahan halal, & 1 \\
\hline & bahan & pengolahan bahan & Pengolahan tidak jelas, & 3 \\
\hline & & & ahan & 5 \\
\hline
\end{tabular}

\section{Tahap 2. Penentuan Nilai Atribut}

Perubahan data non-numerik, seperti sumber, jenis, dan status pengolahan, menjadi data numerik atau kode bahan berupa angka, agar dapat diolah menggunakan metode Hierarchical clustering pada Table 1 kolom 5 .

\section{Tahap 3. Clustering}

Berikut disajikan algoritma proses clustering pada Gambar 2. Hasil clustering dilakukan validasi menggunakan pendekatan diagram alir penentuan status bahan berupa pohon keputusan mengacu ke
LPH LPPOM MUI sehingga diketahui status kehalalan bahan menu setiap tenant.

\section{HASIL DAN PEMBAHASAN}

\section{Pengelompokan Bahan dan Tenant}

Di Kantin CL UB terdapat 262 menu menggunakan 722 bahan. Jenis bahan yang sangat banyak menjadi kendala proses identifikasi. Bahan dibagi menjadi 2 kelompok yaitu bahan kritis (TK) dan bahan non-kritis (NK). 


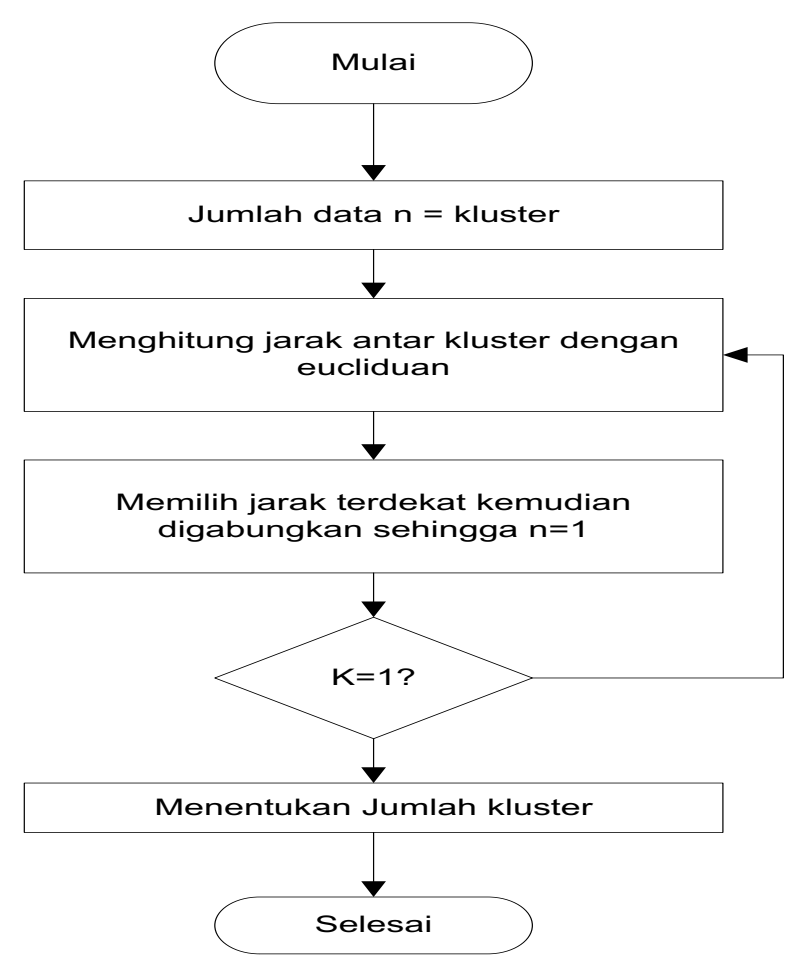

Gambar 2. Digram Alir Hierarchical Clustering

Tabel 2. Kode Tiap Tenant

\begin{tabular}{llc}
\hline No & Tenant & Kode \\
\hline 1 & Bakso \& Mie Lovina IP-UB & $\mathrm{A}$ \\
2 & Soto Sate Buk Win & $\mathrm{B}$ \\
3 & Kedai Pojok Arema & $\mathrm{C}$ \\
4 & Depot Matsari & $\mathrm{D}$ \\
5 & Depot Pak No & $\mathrm{E}$ \\
6 & Mie Ayam Solo & $\mathrm{F}$ \\
7 & Warung Lare Oseng BWI & $\mathrm{G}$ \\
8 & Depot Tahu Telor Salsa Carefull & $\mathrm{H}$ \\
9 & Kuliner Madura "Nyaman Onggu” & $\mathrm{I}$ \\
10 & Depot Rizky & $\mathrm{J}$ \\
11 & Ayam Geprek Cak Per & $\mathrm{K}$ \\
12 & Depot Markisa & $\mathrm{L}$ \\
13 & Depot Lauk Pauk & $\mathrm{M}$ \\
14 & Depot Jakarta 48 & $\mathrm{N}$ \\
15 & Depot Hafi & $\mathrm{O}$ \\
16 & Depot Mama Ucok & $\mathrm{P}$ \\
17 & Depot Anzalnaa & $\mathrm{Q}$ \\
18 & Dapur Mama Dini & $\mathrm{R}$ \\
19 & Depot Mahasiswa Wirausaha & $\mathrm{S}$ \\
20 & Kantin Mie Ijo & $\mathrm{T}$ \\
21 & Dapur 78 & $\mathrm{U}$ \\
22 & Kedai OISHI & $\mathrm{V}$ \\
23 & Kedai Ikan Terbang & $\mathrm{W}$ \\
24 & Kafe CL & $\mathrm{X}$ \\
\hline & &
\end{tabular}

Beberapa jenis bahan dan merk yang sama atau berbeda digunakan oleh banyak tenant. Karena itu, untuk memudahkan identifikasi, setiap tenant diberi kode seperti pada Tabel 2. Kode tersebut dapat memperjelas hasil analisis bahan kritis atau non-kritis dari setiap tenant seperti pada Tabel 3 .

Hasil penentuan nilai atribut dijadikan dasar penentuan klaster bahan. Hasil klaster seluruh bahan dianalisis mengggunakan metode hierarchical clustering. Berikut ini hasil intepretasi keluaran seluruh bahan menggunakan SPSS 19.0.

Tabel 4 menunjukkan jumlah data yang dianalisis sejumlah 722. Nilai atribut sumber bahan minimum 1 dan maksimum 5. Nilai atribut jenis bahan minimum 1 dan maksimum 5. Nilai atribut proses pengolahan minimum 1 dan maksimum 3 . Pada penelitian ini tidak dilakukan standardisasi nilai atribut karena semua objek dianggap sama dan memiliki satuan sama. Rerata nilai sumber bahan 1,6094 dan standar deviasi 1,37132, rerata jenis bahan 2,3906 dan standar deviasi 1,90621, dan rerata status pengolahan 1,1690 dan standar deviasi 0,55662. Standar deviasi menunjukkan sebaran data sampel dan kedekatan setiap data ke rerata sampel.

Tabel 5 menunjukkan rangkuman proses identifikasi kasus clustering. Pada tabel tersebut terdapat objek 722 yang dianalisis dan $100 \%$ valid tanpa ada data hilang. Hal ini menunjukkan proses hierarchical clustering mampu mengelompokkan bahan dengan baik.

Tabel 6 merupakan contoh penjabaran dari Proximity matrix pada tenant Bakso \& Mie Lovina IP UB. Menurut Sitepu et al., (2011) Proximity matrix menunjukkan kemiripan dua objek. Semakin kecil jarak Euclidian, semakin kecil jarak antar dua objek sehingga semakin mirip. 
Tabel 3. Penentuan Nilai Atribut

\begin{tabular}{|c|c|c|c|c|c|c|}
\hline Tenant & No & $\begin{array}{l}\text { Nama Bahan } \\
\text { (tenant) }\end{array}$ & $\begin{array}{l}\text { Merk } \\
\text { Bahan }\end{array}$ & $\begin{array}{c}\text { Sumber } \\
\text { Bahan }\end{array}$ & $\begin{array}{c}\text { Jenis } \\
\text { Bahan }\end{array}$ & $\begin{array}{c}\text { Status } \\
\text { Pengolahan }\end{array}$ \\
\hline \multirow{10}{*}{ 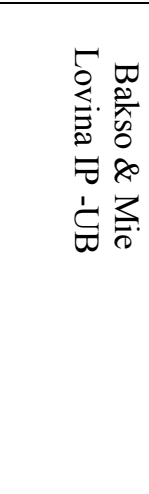 } & 1 & Mie Pangsit (A) & - & 1 & 5 & 3 \\
\hline & 2 & $\begin{array}{l}\text { Tepung } \\
\text { Tapioka(A) }\end{array}$ & $\begin{array}{l}\text { Double } \\
\text { Phoenix }\end{array}$ & 1 & 5 & 1 \\
\hline & 3 & Daging Sapi (A) & - & 5 & 1 & 3 \\
\hline & 4 & Daging Ayam (A) & - & 5 & 1 & 3 \\
\hline & 5 & Kulit Ayam (A) & - & 5 & 1 & 3 \\
\hline & 6 & Tahu (A) & - & 1 & 5 & 1 \\
\hline & 7 & Tempe (A) & - & 1 & 5 & 1 \\
\hline & 8 & Mie Instan (A) & Indomie & 1 & 5 & 1 \\
\hline & 9 & Beras (A) & $\begin{array}{l}\text { Cap } \\
\text { Simbol }\end{array}$ & 1 & 1 & 1 \\
\hline & 10 & Telur Ayam (A) & - & 5 & 1 & 1 \\
\hline
\end{tabular}

Tabel 4. Statistik Diskriptif

\begin{tabular}{lccccc}
\hline & N & Minimum & Maksimum & Rerata & Standar Deviasi \\
\hline Sumber bahan & 722 & 1,00 & 5,00 & 1,6094 & 1,37132 \\
Jenis bahan & 722 & 1,00 & 5,00 & 2,3906 & 1,90621 \\
Status pengolahan & 722 & 1,00 & 3,00 & 1,1690 & 0,55662 \\
Valid N (listwise) & 722 & & & & \\
\hline
\end{tabular}

Tabel 5. Cases Processing Summary

\begin{tabular}{|c|c|c|c|c|}
\hline \multicolumn{5}{|c|}{ Cases } \\
\hline Valid & \multicolumn{2}{|r|}{ Missing } & & \multirow{2}{*}{$\begin{array}{c}\text { Total } \\
\text { Percent }\end{array}$} \\
\hline $\mathrm{N}$ Percent & $\mathrm{N}$ & Percent & & \\
\hline $72100,0 \%$ & \multirow{3}{*}{\multicolumn{2}{|c|}{, $0 \%$}} & & \multirow[t]{3}{*}{$100,0 \%$} \\
\hline 2 & & & 2 & \\
\hline & & & 2 & \\
\hline a. Squared Euclide & & & & \\
\hline
\end{tabular}

$\underline{\text { Tabel 6. Proximity Matrix }}$

\begin{tabular}{lcccc}
\hline \multicolumn{1}{c}{ Kasus } & $\begin{array}{c}\text { 1. Mie } \\
\text { pangsit (A) }\end{array}$ & $\begin{array}{c}\text { 2.Tepung tapioka } \\
\text { (A) }\end{array}$ & $\begin{array}{c}\text { 3.Daging sapi } \\
(\mathbf{A})\end{array}$ & $\begin{array}{c}\text { 4. Daging } \\
\text { ayam (A) }\end{array}$ \\
\hline 1 : Mie pangsit (A) & 0,000 & 12,910 & 12,912 & 12,912 \\
2 : Tepung tapioka (A) & 12,910 & 0,000 & 25,822 & 25,822 \\
3 : Daging sapi (A) & 12,912 & 25,822 & 0,000 & 0,000 \\
4 : Daging ayam (A) & 12,912 & 25,822 & 0,000 & 0,000 \\
\hline
\end{tabular}

Tabel 7. Urutan Pengelompokan

\begin{tabular}{|c|c|c|c|c|c|c|}
\hline \multicolumn{7}{|c|}{ Urutan Pengelompokan } \\
\hline \multirow{2}{*}{$\frac{8}{\frac{2}{2}}$} & \multicolumn{2}{|c|}{ Kombinasi Klaster } & \multirow{2}{*}{ 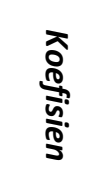 } & \multicolumn{2}{|c|}{$\begin{array}{c}\text { Tahap Klaster Muncul } \\
\text { Pertama }\end{array}$} & \multirow{2}{*}{ 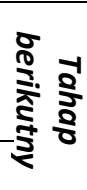 } \\
\hline & Klaster 1 & Klaster 2 & & Klaster 1 & Klaster 2 & \\
\hline 1 & 721 & 722 & ,000 & 0 & 0 & 2 \\
\hline 2 & 2 & 721 & ,000 & 0 & 1 & 8 \\
\hline 3 & 715 & 720 & ,000 & 0 & 0 & 8 \\
\hline 4 & 718 & 719 & ,000 & 0 & 0 & 5 \\
\hline 5 & 141 & 718 &, 000 & 0 & 4 & 7 \\
\hline 6 & 716 & 717 & ,000 & 0 & 0 & 7 \\
\hline 7 & 141 & 716 & ,000 & 5 & 6 & 191 \\
\hline 8 & 2 & 715 & ,000 & 2 & 3 & 10 \\
\hline
\end{tabular}


Tabel 7 merupakan hasil clustering dengan metode "between group linkage". Setelah jarak antar variabel diukur dengan jarak Euclidean, maka dikelompokkan bertingkat. Tahap 1: terbentuk 1 klaster beranggota sampel no 721 dan 722 dengan jarak 0.000 (pada kolom coefficients). Karena proses aglomerasi dimulai dari 2 objek terdekat, maka jarak tersebut terdekat dari seluruh kombinasi jarak 722 bahan. Selanjutnya kolom terakhir (tahap berikut), terlihat angka 2. Hal ini berarti clustering selanjutnya dilakukan melihat tahap 2. Demikian seterusnya dari tahap 2 dilanjutkan ke tahap 8, sampai tahap terakhir. Dari contoh tenant Bakso \& Mie Lovina IP UB (A) maka diperoleh anggota klaster seperti pada Tabel 8.

Tabel 8. Anggota Klaster

\begin{tabular}{lcc}
\hline Kasus & $\mathbf{3}$ & 2 Kalster \\
& Klaster & \\
\hline 1:Mie pangsit (A) & 1 & 1 \\
2:Tepung tapioka (A) & 2 & 2 \\
3:Daging sapi (A) & 3 & 1 \\
4:Daging ayam (A) & 3 & 1 \\
5:Kulit ayam (A) & 3 & 1 \\
6:Tahu (A) & 2 & 2 \\
7:Tempe (A) & 2 & 2 \\
8:Mie instan (A) & 2 & 2 \\
\hline
\end{tabular}

Pada Tabel 9 dapat dilihat pengelompokan bahan menjadi 3 klaster besar yakni bahan nabati, bahan hewani, dan bahan tambahan. Selain itu, terlihat anggota klaster termasuk bahan kritis dan bahan non-kritis. Dari proses ini, diperoleh hasil 209 $(28,95 \%)$ bahan sudah bersertifikat halal dan 513 $(71,05 \%)$ bahan tidak memiliki sertifikat halal. Dari 513 bahan tersebut setelah dikelompokkan terdapat $487(67,45 \%)$ bahan termasuk bahan non-kritis, yang didominasi oleh bahan nabati segar dan sisanya 26
$(3,55 \%)$ termasuk bahan kritis. Meski bahan berjumlah banyak, bahan kritis relatif kecil, karena Kantin CL didedikasikan untuk memproduksi produk halal.

Pada Tabel 9 ada beberapa jenis bahan yang sama, misalnya petis (J) termasuk bahan non-kritis, sedang petis $(\mathrm{H}),(\mathrm{L}),(\mathrm{M})$ tergolong bahan kritis. Hal ini karena, petis yang digunakan tentant $\mathrm{J}$ sudah bersertifikasi halal, sedang petis (H),(L),(M) tidak ada merknya sehingga tidak dapat ditelusuri statusnya. Hierarchical clustering sangat membantu pengelompokan bahan kritis untuk menu kantin yang beragam dan kompleks sehingga menunjang identifikasi status bahan. Penentuan kategori bahan kritis atau non-kritis melalui analisis status sertifikasi halal dan bahan penyusunnya hingga ditentukan statusnya dapat digunakan atau tidak.

\section{Penentuan Status Bahan}

Penentuan status bahan adalah upaya akhir untuk menilai bahan yang selama ini dipakai para tenant kantin dapat digunakan atau perlu diganti ketika menyusun matrik bahan dalam dokumen SJH dan mengajukan sertifikasi halal. Analisis ini mengacu manual book SJH MUI (2008) pada Gambar 3. Hasil Analisis penentuan status bahan pada Tabel 10.

Hasil analisis dari 3,55\% bahan kritis perlu dipastikan statusnya dapat atau tidak digunakan. Bahan-bahan yang perlu dipastikan statusnya dari para tenant adalah bahan daging dan olahan daging yang belum memiliki sertifikat halal. Kaidah umum bahan daging dan olahan daging adalah berasal dari hewan halal, proses penyembelihan sesuai syariat Islam, dan telah memiliki sertifikat halal resmi. Penyembelihan halal memotong 3 saluran dengan sempurna.

Tabel 9. Kategori bahan kritis dan non kritis

\begin{tabular}{|c|c|c|}
\hline Kategori Bahan & $\begin{array}{l}\text { Bahan Kritis } \\
\text { (Kode Tenant) }\end{array}$ & $\begin{array}{l}\text { Bahan Non Kritis } \\
\text { (Kode Tenant) }\end{array}$ \\
\hline Nabati & $\begin{array}{l}\text { Mie Pangsit (A), Kulit Pangsit (A), Tepung Panir (M), } \\
\text { Kweitiau Basah (P), Tempura (X), Lumpia (X) }\end{array}$ & $\begin{array}{l}\text { Tahu (A), Tempe (A), Cabai } \\
\text { Hijau (A), Bawang Putih (A),(B), } \\
\text { Cabai Rawit (A), Merica (A), } \\
\text { Bawang Pre (A), Lada (A), } \\
\text { Beras (B), Kacang (B), Bawang } \\
\text { merah (B), Kecap (B), Cabai } \\
\text { Merah (B), dst. }\end{array}$ \\
\hline Hewani & $\begin{array}{l}\text { Sosis }(J),(K) \text {, Bakso }(X) \text {, Daging Sapi }(A),(I),(N) \text {, Daging } \\
\text { Ayam }(A),(D),(F),(G),(N),(T),(Q) \text { Tulang Usus }(I) \text {, Ampela- } \\
\text { Ati }(Q),(C)\end{array}$ & 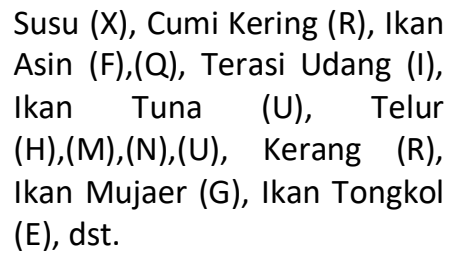 \\
\hline Tambahan & Petis $(\mathrm{H}, \mathrm{L}, \mathrm{M})$, Petis Madura (I) & $\begin{array}{l}\text { Bumbu Kaldu (A), Bumbu } \\
\text { Instan (A), Penyedap Rasa (D), } \\
\text { Petis (J), Saus Tiram (R), Garam } \\
\text { (A), (B), dst. }\end{array}$ \\
\hline
\end{tabular}


Shahdan et al. (2016) dan Shahdan et al. (2017) telah mendiskusikan penyembelihan yang sesuai ajaran Islam. Fatwa MUI No 12 tahun 2009, penyembelihan yang baik memutus saluran darah, kerongkongan, dan tenggorokan (MUI, 2009). Sucipto et al. (2020) telah mendiskusikan pilihan alat penyembelihan ayam untuk mendukung penerapan SJH sehingga dihasilkan daging ayam halal.

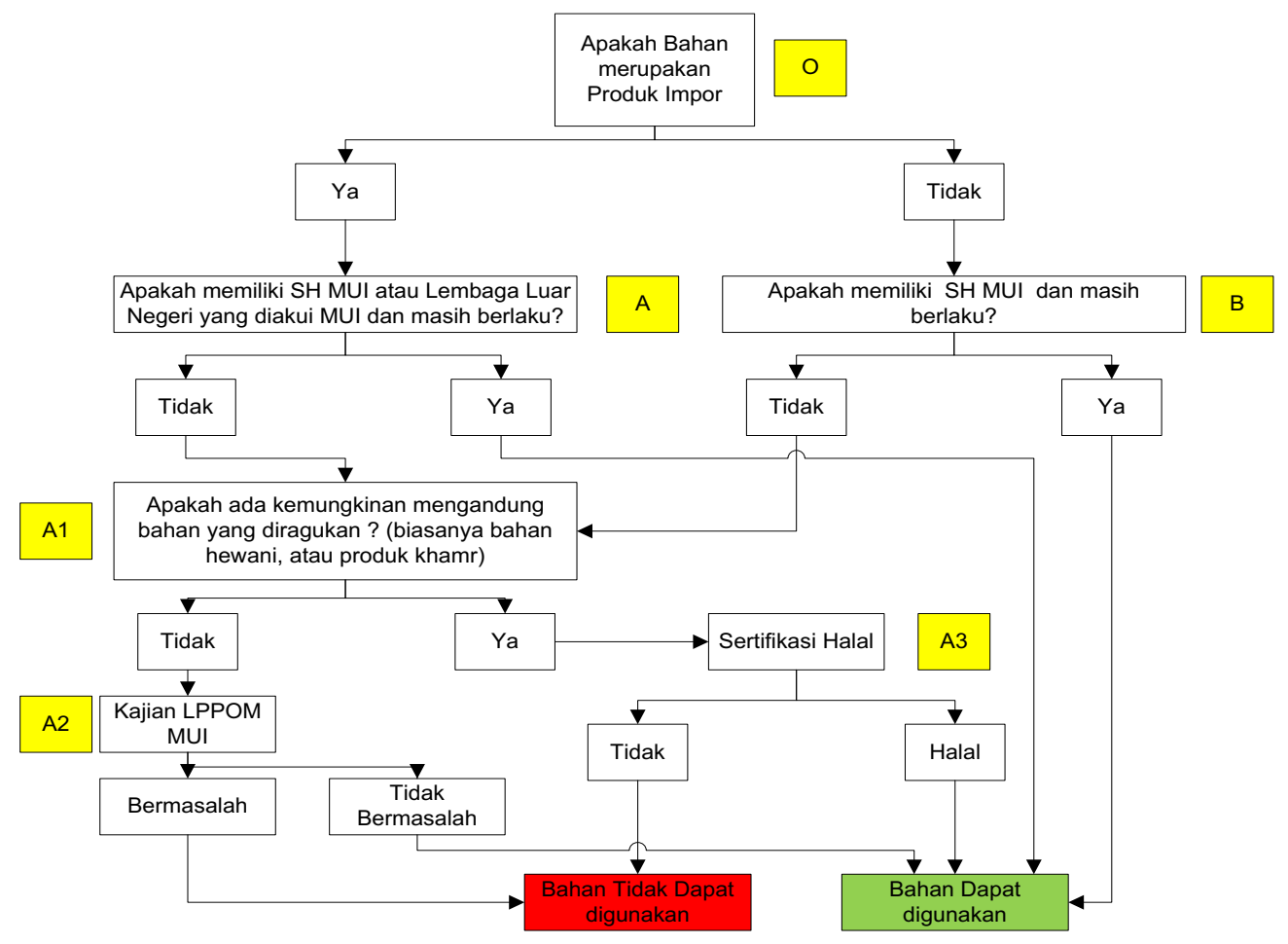

Keterangan:
O : Asal bahan (impor atau local)
A2 : Kajian keberadaan masalah di LPPOM MUI
A : Status sertifikat halal bahan impor
A3 : Status keberadaan sertifikasi halal bahan yang diragukan
A1 : Keberadaan bahan yang diragukan

Gambar 3. Diagram Alir Penentuan Status Bahan (LPPOM MUI, 2008)

Tabel 10. Analisis penentuan status bahan

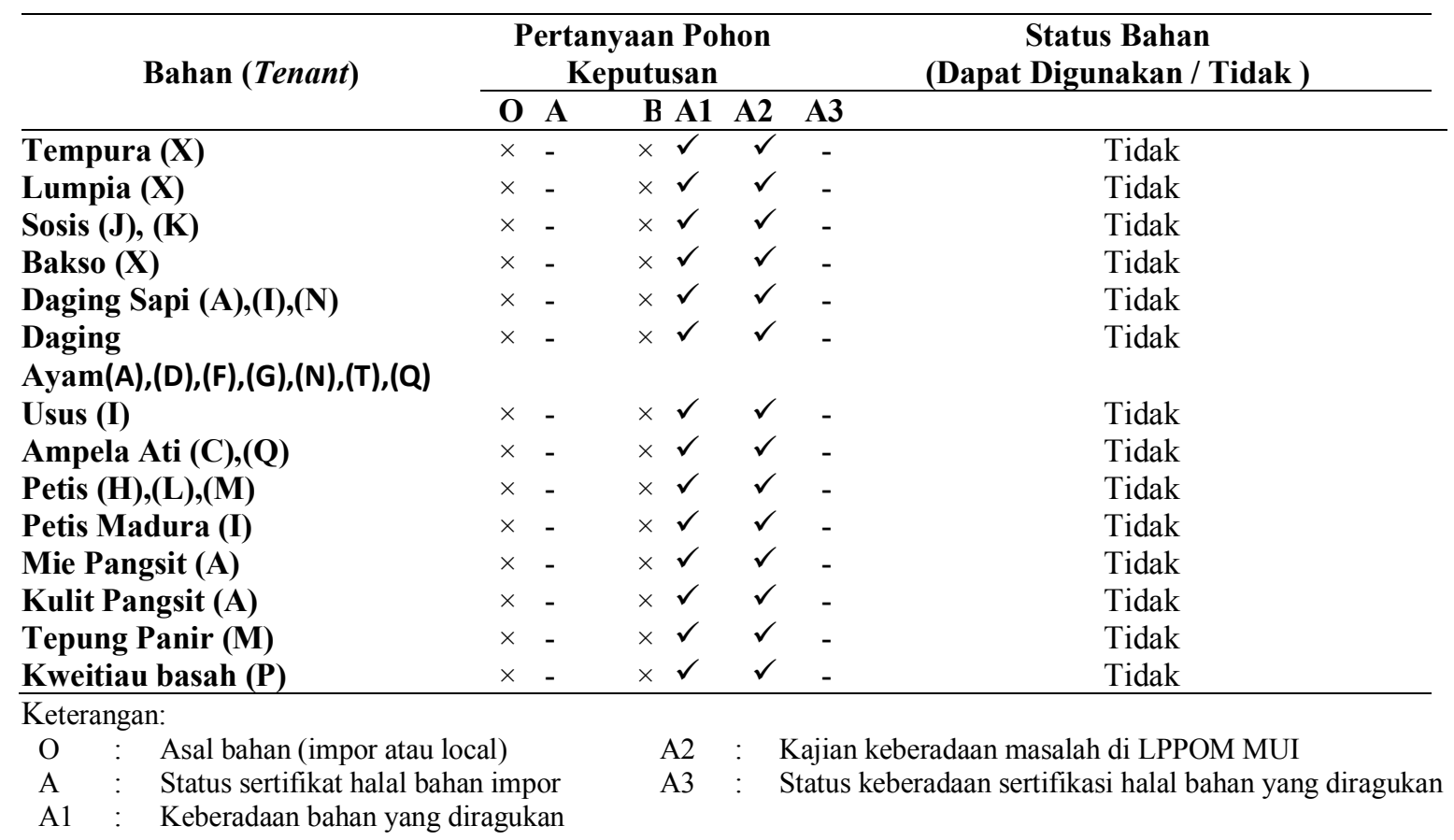


Bahan kritis juga dapat disebabkan keterbatasan kemampuan telusur karena merk bahan tidak jelas. Hal ini terjadi karena tenant membeli bahan grosir tanpa merk. Contohnya adalah tepung panir (M) dan mie pangsit (A) pada Tabel 9 dan Tabel 10 menggunakan bahan utama tepung terigu. Secara teoritis, pengolahan tepung terigu sering ditambah vitamin dan L-sistein. Tepung terigu dari biji gandum, namun sering diperkaya vitamin A (LPPOM MUI, 2012; Roswiem, 2015). Vitamin A biasa disalut agar mudah larut dan tidak mudah rusak selama penyimpanan (LPPOM MUI, 2014). Bahan penyalut selain dari bahan halal seperti gum juga dari bahan syubhat (diragukan kehalalannya) seperti gelatin (Yaqin, 2014). L-sistein merupakan agen improving untuk meningkatkan sifat dan kualitas tepung. Apriyantono (2009) menyatakan L-sistein dapat dibuat dari rambut manusia dan bulu hewan. Bila dibuat dari rambut manusia termasuk bahan haram. $L$ sistein dari bulu hewan harus dipastikan dari hewan halal dan disembelih sesuai ajaran Islam. Karena itu, keberadaan merk bahan penting untuk memperjelas dan memudahkan penelusuran status bahan.

Pengelola kantin CL perlu memberi rekomendasi atau menyediakan pemasok khusus untuk produk daging. Hal ini telah menjadi kebijakan Tim Manajemen Kantin UB. Produk seperti petis, kulit pangsit, mie pangsit dapat diganti produk bersertifikat halal atau menggunakan surat pernyataan proses produksi halal $(\mathrm{PPH})$ dari para penghasil bahan.

\section{Penanganan Bahan yang Tidak Memenuhi Kriteria}

Bahan tidak memenuhi kritera tidak disetujui Lembaga Pemeriksa Halal (LPH). Bahan tersebut perlu penanganan khusus. Semua operasi produksi harus dinyatakan dengan jelas oleh yang berwenang. Jaringan distribusi harus diatur secara legal sejauh mungkin distribusi tersebut dilakukan (Supaat dan Nizam, 2019). Penjaminan logistik bahan harus diperhatikan karena sangat krusial untuk memastikan kehalalan bahan baku, komposisi, pengemasan, penyimpanan dan transportasi agar tidak terkontaminasi (Soon et al., 2017).

Bahan halal sebagai pengganti mesti dipilih dengan pertimbangan ekonomis yaitu harga bersaing, mudah didapat di kota tempat produk diproduksi atau mudah dipesan, dan kualitas bahan sesuai kriteria para tenant. Dengan cara tersebut maka penggantian bahan kritis dengan bahan halal tetap mempertahankan cita rasa menu, kualitas, dan memperkecil resiko peningkatan harga menu. Contoh rekomendasi bahan pengganti pada Tabel 11 .

Bila terdapat pengolahan lanjut, harus dipastikan bahwa bahan yang digunakan memiliki sertifikat halal atau surat keterangan proses produksi halal (PPH) agar terjamin kehalalannya. Daging merupakan bahan mentah hewani melalui proses penyembelihan. Proses penyembelihan dapat menjadikan bahan tersebut halal atau haram sehingga daging sapi, daging ayam, usus, dan ampela ati terkategori HCP A2.

Penggantian bahan perlu reformulasi menu sehingga membutuhkan komitmen para tenant. Komitmen manajemen menjadi salah satu klausul yang diformalkan dalam dokumen tertulis $\mathrm{SJH}$ (LPPOM MUI, 2015). Karena itu, kesadaran para tenant dan pekerja terkait aspek kehalalan perlu terus ditingkatkan melalui berbagai pelatihan internal dan eksternal usaha. Pelatihan ini juga menjadi prasyarat implementasi SJH saat audit lapang oleh LPH. Bukti pelatihan mesti didokumenkan dengan baik. Kompetensi karyawan yang diperoleh saat pelatihan sangat membantu penyusunan matrik bahan dan penentuan bahan kritis dan non-kritis, serta mengimplentasikan SJH di unit usaha.

Tabel 11. Alternatif pengganti bahan

\begin{tabular}{|c|c|c|c|}
\hline Nama Bahan & $\begin{array}{c}\text { Merk Bahan yang } \\
\text { digunakan }\end{array}$ & Alternatif Bahan Pengganti & $\begin{array}{c}\text { Sertifikat Halal / } \\
\text { Surat Proses Produksi } \\
\text { Halal (PPH) }\end{array}$ \\
\hline Tempura (X) & Angelia Frozen Food & Kharisma Frozen, Laras Food, dst & Sertifikat Halal \\
\hline Lumpia (X) & Angelia Frozen Food & Kharisma Frozen, Laras Food, dst & Sertifikat Halal \\
\hline Sosis (J),(K) & - & Bernardi, So Nice, Champ, dst & Sertifikat Halal \\
\hline Bakso (X) & Angelia Frozen Food & Kharisma Frozen, Laras Food, dst & Sertifikat Halal \\
\hline Daging Sapi (A),(I),(N) & - & RPH Kota Malang & Sertifikat Halal \\
\hline Daging Ayam & - & RPA Mualim Broiler Kota Batu & Sertifikat Halal \\
\hline \multicolumn{4}{|l|}{$((A),(D),(F),(G),(N),(T),(Q)$} \\
\hline Usus (I) & - & RPA Mualim Broiler Kota Batu & Sertifikat Halal \\
\hline Ampela Ati (C),(Q) & - & RPA Mualim Broiler Kota Batu & Sertifikat Halal \\
\hline Petis (H) (L) (M) & - & - & Surat PPH \\
\hline Petis Madura (I) & - & Ananta, Ny Siok, dst & Sertifikat Halal \\
\hline Mie Pangsit (A) & - & Gloria, Mie Burung Dara & Sertifikat Halal \\
\hline Kulit Pangsit (A) & - & - & Surat PPH \\
\hline Tepung Panir (M) & - & Fanku, Kobe, dst & Sertifikat Halal \\
\hline Kweitiau Basah (P) & - & La Fonte, dst & Sertifikat Halal \\
\hline
\end{tabular}


Tabel 11 menunjukkan bahan menu setiap tenant di Kantin CL yang belum tersertifikasi halal dan termasuk bahan kritis perlu diganti bahan bersertifikat halal atau surat keterangan proses produksi halal $(\mathrm{PPH})$ dari produsen bahan seperti kulit pangsit (A) dan petis (H), (L), (M). Surat keterangan PPH ini perlu diperiksa LPH saat audit. Untuk keberlanjutan usaha para tenant perlu melakukan identifikasi dan perbandingan berbagai bahan yang sudah jelas status kehalalannya. Alternatif bahan halal dapat diikuti pencarian produk halal di web LPH LPPOM MUI.

\section{Implikasi Manajerial}

Dari proses clustering yang telah dilakukan terdapat problem utama tenant adalah penyediaan daging halal dan bahan bahan-bahan spesifik yang belum bersertifikasi halal dan sulit diperoleh di kota kantin berada. Pengelola kantin CL perlu merekomendasikan atau menyediakan pemasok khusus untuk produk daging. Tim Manajemen Kantin UB perlu menyarankan tenant yang menggunakan bahan seperti petis, kulit pangsit, mie pangsit diganti produk bersertifikat halal atau menggunakan surat keterangan proses produksi halal $(\mathrm{PPH})$ dari pemasok bahan.

Pihak manajemen Kantin CL harus memantau pilihan bahan yang digunakan tenant agar mendukung implementasi SJH. Pemilihan bahan sangat menentukan jaminan halal di Kantin CL sesuai tuntutan UU No 33 Tahun 2014 tentang Jaminan Produk Halal. Hirarcical clustering mempercepat proses identifikasi terkait status kehalalan bahan menu yang kompleks pada kantin sehingga mempercepat penyusunan dokumen $\mathrm{SJH}$ dan proses sertifikasi halal.

\section{KESIMPULAN DAN SARAN}

\section{Kesimpulan}

Analisis terhadap 24 tenant kantin Creative Land Universitas Brawijaya terdapat 262 menu dan menggunakan 722 bahan. Identifikasi status bahan terdapat $29 \%$ bahan bersertifikat halal dan $71 \%$ bahan tidak bersertifikat halal. Klaster bahan tidak bersertifikat halal $67 \%$ merupakan bahan non-kritis dan 3,55\% bahan kritis. Bahan kritis terutama disebabkan merk bahan tidak jelas, penyembelihan bahan daging dan olahan daging belum bersertifikasi halal. Bahan kritis mesti diganti bahan bersertifikat halal atau surat pernyataan proses produksi halal (PPH) dari produsen bahan yang perlu diverifikasi Lembaga Pemeriksa Halal (LPH). Metode hierarchical clustering memudahkan identifikasi bahan menu kantin yang kompleks sehingga memudahkan penyusunan dokumen untuk menunjang sertifikasi halal.

\section{Saran}

Pengelola kantin CL perlu memantau penggantian bahan tidak memenuhi kriteria setiap tenant. Bahan daging segar perlu pemasok tetap dari rumah potong hewan bersertifikasi halal. Pada penelitian ini clustering terbatas untuk menentukan bahan kritis dan non kritis. Selanjutnya perlu diteliti clustering jenis bahan kritis dapat diganti bahan bersertifikasi halal dan jenis bahan kritis yang dapat diganti bahan yang dilengkapi surat keterangan proses produksi halal $(\mathrm{PPH})$ dari produsen yang perlu diverifikasi lembaga pemeriksa halal (LPH).

\section{UCAPAN TERIMA KASIH}

Tim penulis mengucapkan terima kasih ke Lembaga Penelitian dan Pengabdian Masyarakat (LPPM) Universitas Brawijaya yang telah membantu publikasi melalui dana pengembangan pusat studi dan kelompok penelitian tahun 2020 dengan nomor kontrak 1103.7/UN10.C10/PN/2020.

\section{DAFTAR PUSTAKA}

Allata S, Valero A, dan Benhadja L. 2017. Implementation of traceability and food safety systems (HACCP) under the ISO 22000:2005 standard in North Africa: The case study of an ice cream company in Algeria. Food Control. 79: $239-253$

Apriyantono, A. 2009. Titik Kritis Kehalalan Produk Bakery dan Kue. Bandung: Penerbit Kiblat.

Dewi LJE. 2012. Pengelompokan Data dengan Metode Klasterisasi Hierarki. Jurnal Pendidik Tek Kejuru. 6(1): 17-24.

Gupta V dan Rastogi A. 2017. Survey on Classification of Clustering Technique. International Joural Adv Res Comput Commun Eng. 6(4): 753-760.

Hasan MH, Sezalin A, dan Safi'ah S. 2015. Knowledge and practice for implementing internal halal assurance system among halal executives. Journal Asian Social Science. 11(17): 57-66.

LPPOM MUI. 2008. Panduan Umum Sistem Jaminan Halal LPPOM MUI. LPPOM MUI. Jakarta

LPPOM MUI. 2012. Persyaratan Bahan Pangan Halal. LPPOM MUI. LPPOM. Jakarta

LPPOM MUI. 2014. Pedoman Pemenuhan Kriteria Sistem Jaminan Halal di Industri Pengolahan. LPPOM MUI. Jakarta.

LPPOM MUI. 2015. Pemenuhan Kriteria Sistem Jaminan Halal di Restoran HAS 23102. LPPOM MUI. Jakarta.

Majelis Ulama Indonesia (MUI). 2009. Fatwa MUI No 12 Tahun 2009 tentang penyembelihan halal. MUI.

Nurmaydha A, Sucipto S, dan Mustaniroh SA. 2018. Konsep model sistem jaminan halal (SJH) pada restoran hotel syariah (Studi Kasus di Unida 
Gontor Inn, Universitas Darussalam Gontor. Jurnal Teknologi Pertanian. 19 (3): 141-152.

Nurrachmi R. 2017. The Global Development of Halal Food Industry: A Survey. Tazkia Islamic Finance Bus Rev. 11(1): 39-59.

Osimani A, Aquilanti L, Tavoletti S, Clementi F. 2013. Evaluation of the HACCP system in a university canteen: microbiological monitoring and internal auditing as verification tools. International Journal Environ Res Public Health. 10(4):1572-85.

http://dx.doi.org/doi:10.3390/ijerph10041572.

Osimani A, Aquilanti L, dan Clementi F. 2015. Evaluation of HACCP system implementation on the quality of mixed fresh-cut salad prepared in a university canteen: a case study. Journal Environ Health. 77(6): 78-84.

Osimani A, Milanović V, Aquilanti L, Polverigiani S, Garofalo C, Clementi F. 2018. Hygiene auditing in mass catering: a 4-year study in a university canteen. Public Health. 159:17-20. http://dx.doi.org/10.1016/j.puhe.2018.03.015.

Perdani CG, Angelina R, dan Sucipto S. 2017. Evaluation of halal assurance system in hotel restaurant with shariah concept to support halal tourism (Case study at Hotel Fariz Syariah Malang). Proceeding The 1st International Conference on Sustainable Tourism. ISBN: 978-602-50301-5-4. hal. 285-295.

Perdani CG, Chasanah NU, dan Sucipto S. 2018. Evaluation of halal assurance system (HAS) implementation on bakery products processing in small and medium enterprises (case study in $\mathrm{X}$ Bakery Batu, East Java). IOP Conference Series: Earth and Environmental Science. 131 (2018) 012023. Doi: 10.1088/17551315/131/1/012023.

Roswiem AP. 2015. Buku Saku Produk Halal: Makanan dan Minuman. Jakarta: Penerbit Republika.

Shahdan IA, Regenstein JM, dan Shahabuddin ASM, Rahman MT. 2016. Developing control points for halal slaughtering of poultry. Poult Sci. 95(7): 1680-1692.

Shahdan IA, Regenstein JM, dan Rahman MT. 2017. Critical limits for the control points for halal poultry slaughter. Poult Science. 96(7): 19701981. http://dx.doi.org/10.3382/ps/pew427.

Saxena A, Prasad M, Gupta A, Bharil N, Patel OP, Tiwari A, Er MJ, Ding W, Lin CT. 2017. A Review of clustering techniques and developments. Neurocomput. 267: 664-681.

Singh S dan Srivastava S. 2020. Review of Clustering Techniques in Control System. Procedia Comput Sci. 173: 272-280.

Sitepu R, Irmeilyana I, dan Gultom B. 2011. Analisis cluster terhadap tingkat pencemaran udara pada sektor industri di Sumatera Selatan. Jurnal Penelitian Sains. 14(3):11-17.

Soon JM, Chandia M, Regenstein JM. 2017. Halal Integrity in The Food Supply Chain. Br Food Journal. 119 (1): 39-51.

Sucipto S, Astuti R, dan Harkalih GB. 2016a. Identifikasi titik kritis kehalalan dan keamanan produksi mie goreng skala kecil di sekitar kampus perguruan tinggi Kota Malang. Prosiding Seminar Nasional Universitas Darusalam Gontor. Ponorogo. 7 September 2016.

Sucipto S, Astuti R, dan Wurnaningsih S. 2016 b. Analisis implementasi sistem jaminan halal (SJH) di usaha waralaba pangan (Studi kasus di waralaba bakso X). Proceeding Seminar Nasional dan Lokakarya FKPT-TPI 2016. Universitas Jambi. 31 Oktober - 1 November 2016.

Sucipto S, Rahman F, dan Mustaniroh S. 2018. Analisis Penilaian Konsumen Terhadap Kinerja kantin Perguruan Tinggi. Industria: Jurnal Teknik Manajemen Agroindustri. 7(2): 95-106.

Sucipto S, Wardani RI, Kamal MA, Setiyawan DT. 2020. Analisis teknoekonomi alat penyembelihan ayam untuk mendukung implementasi sistem jaminan halal. Jurnal Teknologi Industri Pertanian. 30(1): 72-81.

Sukoso S, Wiryawan A, Kusnadi J, Sucipto S, Prihanto AA, Sukarna MI, Harimurti H. 2020. Ekosistem industri halal. Jakarta: Departemen Ekonomi da Keuangan Syariah - Bank Indonesia.

Supaat SH, dan Nizam NZ. 2019. Marketing Potential of Halal Food Products. International Journal Recent Technol Eng. 8(1): 156-161.

Undang-Undang No 33 Tahun 2014 tentang Jaminan Produk Halal.

Wallace CA, Powell SC, dan Holyoak L. 2005. Development of methods for standardised HACCP assessment. Br Food Journal. 107(10): 723-742.

Wallace CA, Holyoak L, Powell SC, Dykes FC. 2014. HACCP-The difficulty with Hazard Analysis. Food Control. 35: 233-240.

Wirawan NZM, Wiranatha AS, dan Hartiati A. 2018. Strategi Pengembangan Usaha Produksi Tempura Ikan Pada Skala Usaha Rumah Tangga (Studi Kasus Tempura Ikan X Kota Denpasar, Bali) Jurnal Rekayasa Manajeman Agroindustri. 6(1): 57-70.

Yaqin A. 2014. Halal di Era Modern: Kupas Tuntas Halal Haram Produk Pangan, Obat dan Kosmetik di Sekita Kita. Surabaya: Majelis Ulama Indonesia Provinsi Jawa Timur. 